\title{
THE ECONOMIC VALUE OF WATER POWER.
}

\author{
POINTS IN FAVOR OF WATER-DRIVEN WORHS.
}

IN his presidential address at the Technical High School Fredericiana, in Karlsruhe, says the Electrical Review (London), the rector, Prof. Dr. Rehbock, the purchase of whose plans for the Murgthal Barrage by the Baden government has brought the resource of this country for electrical water-power schemes prominently into the foreground, gave an interestin résumé of the economic value of water power as compared with the steam-generated power. After tracin the application of mechanical power to the use of mankind from its infancy, the professor laid stres upon the fact that steam-driven, as compared with water-driven, power works present the advantage that they may be erected anywhere; thus costly transmis they may be erected anywhere; thus costly transmis-
sion of power over long distances is avoided, while in many parts of the world, especially in low-lyin parts, no water power is available. Another important factor is that heat-driven works can always be utilized to their full capacity, while water-driven works, unless provided with sufficiently large storage reservoirs, have to reduce the

The points in favor of water-driven works are that they are cleaner, do not vitiate the atmosphere, an are less dependent upon the ability or willingness of the staff (practically unaffected by strikes). They ar perfectly independent of the difficulties connected with the supply of fuel, and, above all, they produce energ. at a low cost

The cost of the unit of energy is naturally the most teiling factor in this comparison. Under the best possible conditions, i. e., when erected near coal de posits and with regular and continuous work, heat driven power works cannot produce a kilowatt-hou under 0.25 cent to 0.5 cent, equal to 0.38 cent to 0.75 cent at the switchboard. If the demand is subject to great variations, as, for instance, in light and railway supply stations, and when coal has to be obtained from a distance, that cost is often more than doubled. High-pressure water-power works are able to produce the power at one-half or one-third less, and even the low-pressure works, though more expensive, even the low-pressure works, though more expensive,
produce power at a much lower cost than it is possible produce power at a much low
for heat-driven works to do.

In any important power work it is a question of providing many millions-sometimes more than 100 millions-of such units per year, and this means an economic advantage of such great value that it will compensate the mountainous districts, which are rich in water, for any disadvantage they present as compared with the flat country districts.

The countries in which water powers have been exploited in a large way, especially Switzerland, Austria and Upper Italy, have already found considerable profit by their venture. The rapid economic advance in this direction which has taken place in the last few years is, above all, due to the exploitation of the large water powers of the Alpine rivers.

It is at present not possible to say with certainty how far the water powers of any country will be able to cover the energy required. We can approximately estimate the power contained in the flowing river of some parts of the world's surface, where we know the area of the country, average height above sea level, evaporation and rainfall, and quantity of water flowing into the sea. What part of this theoretically available material can be put into practical use cannot be estimated exactly without devoting to it a study and labor requiring much time, as the relation of the available supply to the production of energy varies available supply to the production of energy varies
very largely, and is dependent upon local conditions, supply of fuel, etc.

Theoretically, the energy of the flowing waters on the world's surface aggregates 8,000 million horsepower, or 143 horse-power per square mile, and 5 horse-power per inhabitant. In Germany these figure represent. a total of $16,000,000$ horse-power, or 80 horse-power per square mile, and about $1 \frac{1 / 4}{4}$ horse-
power per inhabitant. The Grand Duchy of Baden power per inhabitant. quite apart from the power derivable from the Rhine, 1,000,000 horse-power, equal to 172 horse power per square mile, or $1 / 2$ horse-power per inhabitant. The power obtainable from the Baden shore of the Rhine would increase these figures to $2,600,000$ horse-power; 445 horse-power per square mile, and $11 \frac{1}{4}$ horse-power per inhaitant. This means that Gernany has only half of the world's average, while Baden has more than three times as much as far as area is concerned, although the density of the population reduces the figures to $1 \frac{11 / 4}{4}$ horse-power per inhabitant. In consequence of its mountains, heavy Rhine, the Grand Duchy of Baden is comparatively very rich in water power.

Although no reliable estimate can be made of the world's power supply derivable from water power, it supply all that there exists more than sufficient to at one-sixteenth of the total, an estimate which is really much too low, there will be $500,000,000$ horse power, or 9 horse-power per square mile, which is ten times as much as the equivalent of the 1,000 million tons of coal, the demand on the coal resources in $190 \%$. This is a most satisfactory circumstance, as the coal deposits of many civilized countries may be said only to be sufficient for the lifetime of a few generations, while the large deposits of China will only last for another few centuries if the demand keeps on in creasing at its present rate.

While thus the world's supply is assured, the con ditions in the different countries are very different. The apparently available supply of 2 to 2.5 million horse-power in Germany is not equal even to the present demand. Among the German States, Baden takes the first place with about eight times of available power, while it is only second to Switzerland as regards all European States, and with the development of Lake Constance it could be made to take the first place in Europe among the countries possessing first place in
water power.

At a low estimate, the cost would be 0.5 cen per horse-power per hour in unregulated high-preswhere the installation is costly, but where, the Rhine, hand, the supply fluctuates very little. In high-pressure works regulated by storage reservoirs the cost sure works regulated by storage reservoirs the cost
would be 0.25 cent per horse-power-hour; those works may be estimated to cover 25 per cent of the total. The total water power available in Baden, at a rough but low estimate, represents an annual profit of $\$ 3,000,000$ on a capital of $\$ 75,000,000$. This represents
a saving of two million tons of coal, or $\$ 7,500,000$, and each 25 cents rise per ton of coal means a further saving of $\$ 500,000$.

According to Mr. H. M. Wilson, in a recent issue of Power, there is now a total of 4,500,000 horse-power in the United States developed from water sources, and the investigations by the government lead to the belief that this can be increased to $10,000,000$. The water resources branch of the Geological Survey is view to ascertaining their availability for the production of power for the irrigation of arid lands, or the draining of swamp lands and for domestic uses. Its work will result in conserving the water supply by the construction of reservoirs for the storage of flood and the increase of dry-season discharges.

As yet, no estimate ố even an approximate nature can be made of the water flowing perennially in our streams, or which may be impounded in storage reservoirs, and which may be made available for utilization in generating power. It is well known that but a small proportion of the available water power in the streams is as yet so utilized. Unfortunately no sta-
tistics have been gathered of the present condition of the development of water powers or their future posthe development of water powers or their future pos-
sibilities. The following approximate data are presented in the light of the knowledge of the topography and hydrography of the United States, garnered from employees in various branches of that service.

In New England there is developed 1,000,000 horsepower, and there may be ultimately available for power purposes a total of 1,500,000 horse-power. In the Great Lakes region the present development is $1,250,000$ horse-power with a possible development of $4,000,000$. In the Piedmont region on the Atlantic and south Atlantic slopes, 1,250,000 horse-power is now developed, with $3,000,000$ possible of development. In the central Northwest 500,000 horse-power has been developed, with a total of $1,000,000$ possible. In the Rocky mountain and Pacific regions there is now $1,500,000$ horse-power in operation, with $5,000,000$ possible. In consequence of the water resources branch sible. In consequence of the water resources branch
there has been added in recent years nearly $1,000,000$ horse-power from water sources. All this power is of value in performing its share of conserving the fuel supply of the country.

A good example of how the development of one industry helps another is found in an order for manganese steel disks recently placed in Milwaukee. This firm, in addition to manufacturing magnetic clutches, makes a specialty of lifting magnets for handling pig iron and scrap metal. The growth of this latter business and the natural desire of the manufacturers to perfect every detail of their product has led to the adoption of manganese steel for coil shields-the coil shields being the flat disk fastened to the under side of the lifting magnet for the double purpose of protecting the magnetizing coil and interposing between the two poles of the magnet an area of non-magnetic material. Brass, which is non-magnetic, has heretofore een used for this purpose. Ordinary steel will not do because it is a magnetic metal and would serve to conduct the magnetic lines of force from pole to pole instead of compelling them to seek a passage through the material to be lifted. Manganese steel seems to be the ideal metal for this purpose. It is non-magnetic, like brass, and infinitely harder-so hard, in fact, that the continued hammering of the pig iron or other metal on the under surface of the magnet makes not the slightest impression on it. The 50-inch magnets recently furnished to a number of steel mills in the Pittsburg district are all equipped with manganese
steel coil shields instead of with the brass coil shields formerly used.-Machinery.

\section{RECENT DEVELOPMENT OF THE GAS} TURBINE.

By Alfred Barbezat.

The first experiments with gas turbines were made with a small turbine of the same type as the De Laval steam turbine, capable of developing about 30 horsepower, and after noting the performances of this machine when driven by compressed air alone, arrangements were made to use it in connection with a combustion chamber, delivering the products of the combustion of liquid hydro-carbon fuel at constant pressure through a nozzle upon the blades of the turbine. The combustion chamber is provided with a refractory lining, and in dealing with such high temperatures of combustion as are met with in engines of this kind, the temperature of combustion being over $3,200 \mathrm{deg}$. F., the best refractory lining has been found to be carborundum, this material being a product of the electris furnace, and thus having already sustained a higher temperature than that in the turbine combustion cham ber. An elastic backing of asbestos provides for the expansion of the carborundum lining. The nozzles through which the cases are discharged are also made of carborundum. In addition to the refractory lining, the combustion chamber must be provided with a water jacket in the form of a coil of pipe imbedded in the metal of the chamber walls. When the water has circulated in the jacket tube, it is sent through small holes into the combustion gases just before they enter the nozzle, and the water is there converted into steam which acts to lower the temperature of the issuing
gases to a point where they will not injure the blades of the turbine.

In order to obtain the desired result of a machine In order to obtain the desired result of a machine
involving only rotary motion, it has been found necessary that the compressed air, by which the combustion chamber is fed, should be produced, not by a reciprocating combustion compressor, but by some form of rotary motion, preferably so arranged that it can be coupled directly to the turbine itself. This means that the complete gas turbine must also include a rotary air compressor, and that such a compressor must have a high efficiency in itself, otherwise it will produce such a large proportion of negative work as to detract materially from the efficiency of the compound machine.

After several experiments, a multiple turbine compressor was decided upon, which was found to be capable of delivering one cubic meter of air per second, at a pressure of six or seven atmospheres, with an efficiency ranging between 60 and 70 per cent. A largebuilt, and in this machine the compressor is found to absorb about one-half of the power developed by the turbine. The machine when running at about 4,000 revolutions per minute develops about 300 horse-power over and above the negative work absorbed by the compressor. It is stated. however, that the thermal efficiency of the machine is not as yet as high as that of a reciprocating gas engine. During the past few months a practical application of the gas turbine has been made in connection with the operation of submarine torpedoes. The turbine made for this purpose developed 120 horse-power at a speed of 1,000 revolutions per minute. The weight of the turbine alone is about 2.86 pounds per horse-power.

While the gas turbine is, of course, still in its experimental stage, it has mađe a material advance during the past year, the 300-horse-power compound compressor turbine being an accomplished fact, and a number of 120-horse-power machines of special type being actually installed for service. When this rate of progress is compared with the time required to bring the reciprocating gas engine to its present state of perfection, there appears to be a reason for encouragement and interest in this form of gas engine.Sassier's Magazine. 